2021, Volume 16, ATEE 2020 - Winter Conference. Teacher Education for Promoting WellBeing in School. Suceava, 2020, pages: 430-440|

https://doi.org/10.18662/lumproc/atee2020/30

\section{Anxiety Tests in Primary School}

Alina RUXANDA (ŞUHAN) ${ }^{1}$

${ }^{1}$ Student, University Stefan cel Mare from Suceava, Romania, e-mail: alina.ruxanda@yahoo.com
Abstract: The purpose of this paper is to present both theoretical and practical aspects related to student's test anxiety. The role of this paper is to inform the teachers about haw the word" test" should be used in the school context and to highlight the aspects of anxiety and everything that lies behind this rich subject. The main objective underlying this paper is the detailed analysis of what anxiety means and haw it manifests itself among the students. The paper is structured of 3 chapters, two of them presenting the theoretical part and one practical part. In the first part called, Theoretical Approach" the paper aims to analyse the following: anxiety, anxiety theories and contemporary theories and implications of anxiety towards the test. In the second chapter called, Anxiety and stress towards tests" the paper focuses on the following aspects: anxiety about test, anxiety disorders and their effects on personality development, the role of tests in education children of primary school, blocking anxiety and recovering from failure, affectivity and perfectionism. In the third chapter named, the research methodology" I will try to analyse haw children are affected during the assessment and haw high their level of anxiety is when they are faced with these situations. Also, in performing the processing and interpretation of the data from this research, the statistical method was used. Thus, after centralizing the results of the students participating in the study, we reached the following conclusions: during the tests some of students trembled their hands, often students forget what they have learned or have problems in remembering. Many students do not give $100 \%$ performance when undergoing tests because they are stressed, became anxious and they block. The teacher has to teach children that the role of testing is to figure out where you went wrong or what needs to be improved. From study the material needed for this paper I was able to discover what each child (even myself) felt and lived when he beard the word, test".

Keywords: anxiety; tests; stress; students; anxiety tests.

How to cite: Ruxanda (Şuhan), A. (2021). Anxiety Tests in Primary School. In O. Clipa (vol. ed.), Lumen Proceedings: Vol. 16. ATEE 2020 - Winter Conference. Teacher Education for Promoting Well-Being in School. Suceava, 2020 (pp. 430-440). Iasi, Romania: LUMEN Publishing House.

https://doi.org/10.18662/lumproc/atee2020/30 


\section{Introduction}

In a world where children want to enter the mysteries of knowledge and the mysteries that life offers them, the school comes to their aid by offering them various opportunities to discover everything they are looking for. Once they have stepped on the threshold of school, students enter a world from which only they decide if they will ever leave. That world will not be without adventures at all, on the contrary it will be the mysterious place where any child is formed on his own.

In this world are active two main characters who depend on each other in all given actions: the teacher and the student. The teacher is the guide and the teacher who helps the child to discover everything that is called "information" and the child is the one who shows the teacher that what he discovers is beneficial in different situations.

The conflict between these characters occurs when the teacher pronounces the word "test" or "evaluation". The child's first contact with this word is visible on everyone's face because it involuntarily produces a change. The word "test" is like a light bulb in the minds of students.

The topic "Anxiety about tests in primary education" that I chose for this paper seemed very interesting, attractive and even debatable for both children and teachers. From studying the material needed for this paper I managed to discover what each child (even me) felt, lived when he heard the word "test". All the new information discovered will help me in the future in my profession, will guide me in educating children and will be my support in overcoming complicated situations before and after tests. I don't think there is a child, student or even a person who does not react to the word "test". So in primary education the teacher has a very important role in educating children even in the first grades. He is the one who needs to know how and when to use the word "test" in front of children of different ages.

All children are curious to enter the art of writing, the art of reading, the world of stories and the world of games. But this start in the world of discoveries can be stopped interrupted or blocked by the utterance of the mysterious word "test". stories and games, has its purpose. It helps children understand the purpose and role of "tests" in any situation. Every child should have in mind the idea that the test is the step towards the beginning of a new "adventure". The teacher is the one who offers the child cognitive and emotional support both before the tests and after its completion. This paper aims to present both the theoretical and practical aspects related to students' test anxiety. The role of this paper is to inform teachers about how 
they should use the word "test" in the school context and to highlight the aspects of anxiety and everything behind this rich subject.

The main objective behind this paper is the detailed analysis of what anxiety means and how it manifests itself as well as providing directions regarding the use of the word "test" when it comes to students.

The case study presents in addition to the theoretical and practical aspects related to this topic, namely anxiety about tests to young students. With the help of this case study, I want to highlight the effects that testing has on students and provide some guidance on what exactly triggers student anxiety during testing.

Closer collaboration and transparency regarding the relationship between teacher and student is especially important and therefore this is an important factor in determining the level of anxiety of students during testing.

Research on test anxiety has thrived on the one hand due to an increase in the number of people testing situations in modern society and on the other hand by conducting tests and seeing the long-term consequences in social and clinical educational problems.

Test anxiety is clearly seen as the key to the problems surrounding psycho-educational testing or as a source of both under-realization and psychological distress. So in the research part we aimed to highlight the effects that testing has on children, highlighting the emotions that children have when tested and identifying the main feelings that are highlighted during testing.

\section{Literature review and Research Problem}

„Research on test anxiety has a long and rich history. The first studies were published in 1914. In 1984, Sarason and Mandler published a series of studies, in which they used the concept under the name that is known today in specialized jargon. Through these studies, the authors focused on the relationship between test anxiety and performance on various cognitive tests. They provided the theoretical basis for the development and refinement of the first tool in the field of assessing individual differences in test anxiety" (Sarason, 1984; Popa, 2018)

"In the next 20 years, notable progress has been made in conceptualizing test anxiety, leading to numerous explanatory models. The intensive concerns of researchers in many countries (USA, Germany, Japan, India, Israel, Turkey, Hungary) have materialized in a corpus of rich observations as well as in the notable increase in the number of scientific publications on anxiety about testing." (Chapell et al., 2005;) 
"Test anxiety refers to a set of behavioral, psychological phenomena and responses that accompany interest in negative consequences or failure in an examination or assessment situation." (Veiga et al., 2016).

According to Shaked, about $30 \%$ of all American students and students had some level of test anxiety" (Shaked et al., 1996) Test anxiety is a combination of physiological challenges, stress, and bodily symptoms, along with anxiety, fear, fear of failure, and catastrophization that occur before or during test situations. It is a physiological condition in which students experience extreme stress, and discomfort during and / or before taking a test. This anxiety creates significant barriers to learning and performance.

Research suggests that high levels of emotional distress have a direct correlation with reduced academic performance and the overall dropout rate of students. Test anxiety can have broader consequences, negatively affecting a student's social, emotional, and behavioral development as well as their feelings about themselves and school.

"Students with test anxiety are characterized by a low and limited response to assessment situations tending to see these test situations as a personal threat. When exposed to evaluation situations, they tend to react with increased anxiety, mental disorganization, stress, and mental challenge" (Spielberger \& Vagg, 1995).

The entire research activity on this topic revealed a number of problems encountered in students' behavior and manifestations before, during and after a school assessment.

Tests or examination (informal, examination or assessment) is an assessment designed to measure those responsible for knowledge, skills, abilities, mental opportunities or classifications in other subjects. skill sets.

The tests vary according to style, rigor and necessity. For example: in a test in which the closed book is usually needed by the testator or must rely on memory to answer certain items (articles) while in a test with the open book, a tester could use one or more additional tools such as a reference book or computer to answer items.

So talking about these appears in addition to the problematic word "test" and another word with special interpretations called "anxiety".

The etymology of the word "anxiety" comes from the Latin language where "angels" meant "strangulation", which leads us to think of strangulation, or blockage. In other words, the original meaning of this term anxiety, which in Latin translates as "anxietas," meant that experience of insecurity, fear, or dread. We can clearly say that there is a big difference between anxiety and fear and that anxiety is something chronic and fear is a passing episode. 
We can talk about fear since ancient times. Both history and literature provide us with clear examples. First of all, we can talk about the Greek physician Hippocrates who said of Damocles that he could not cross any bridge or walk past any precipice. In fact, the renowned author Shakespeare, in his play "The Merchant of Venice" highlighted the phobia of cats, and later, Descartes explained that some people could not stand the smell of roses at all or when they saw cats panicked. Although these symptoms felt by different people are very old, only in the middle of the nineteenth century they were considered as belonging to the clinical field.

Many researchers argue that any fear that is so strong that it can prevent a person from performing an action is, in fact, a pathological reaction.

Anxiety can be defined as a fear, without having a well-defined object, while phobia can be defined as anxiety as a fear but in this case the object is well defined (for example: by animals, by height, by spiders etc). It is also highlighted that in phobias we can include other fears, but which have a more abstract character (for example: fear of losing control of situations, fear of being alone, fear of being rejected, fear responsibility etc).

In 1936, the psychoanalyst Freud introduced the term "anxiety." $\mathrm{He}$ was of the opinion that anxiety refers to and is a consequence of sexual tensions that are repressed. Later, he replaced the term anxiety with something broader, which was defined as an alarm signal about the danger.

Later, in 2002, Neagoe and Jordan define anxiety in a different way, namely "Anxiety actually occurs as a reaction to stress along with other effects, defense mechanisms and various defense reactions" (Neagoe \& Jordan, 2002). They also talk about the effects of anxiety, which, in their view, are largely negative. Also, the effects are complex and are evident in human interaction; sometimes these consequences can help you adapt and even perform in certain areas / situations.

We can say that the feature of anxiety would be the predisposition, which is a function of an experience lived in the past that the individual feels at some point in his life, its character being an internalized one. Anxiety, characterized from the point of view of a condition, is defined as a situational episode, which occurs because of stressful moments that occur in the person's life. Even if anxiety can be viewed from two perspectives, namely the trait and the state, it depends on person to another and the contexts in which it manifests.

Test anxiety is a combination of physiological challenges, stress, and bodily symptoms, along with anxiety, fear, fear of failure, and catastrophizing that occur before or during test situations. It is a physiological condition in which students experience extreme stress, and 
discomfort during and / or before taking a test. This anxiety creates significant barriers to learning and performance. Initially, research on test anxiety was aimed at identifying the relevance of anxiety not only for testing but also during testing. hypotheses:

To carry out this case study we had in view the following

口 "We assume that students become anxious when they are tested."

$\square$ "We assume that the evaluation is influenced by certain factors."

In the third chapter named, The research methodology" I will try to analyze haw children are affected during the assessment and haw high their level of anxiety is when they are faced with these situations. Also, in this case study we analyzed the factors that influence the evaluation from the perspective of teachers.

The objectives of the research are:

- encouraging students that testing is not a bad method of assessment

- identify the connection between testing and feelings and emotions that occur when students are tested

- stating the reasons why students become anxious when subjected to tests

- identifying the factors that influence the evaluation

\section{Research methods}

\section{Method}

The pedagogical research, from Muster's perspective, is described in the following way, an investigation delimited precisely as a theme, to a restricted question, arising in the process of perfecting the learning, education and which requires a certain, thorough, reasoned answer, scientifically in question" (Seymour \& Kety, 1985).

The sample the tests were performed on a number of 56 subjects, of which, 7 teachers and 49 children. The tests were performed for the third and fourth grades.

Procedures. For conducting the research, we investigated which is a direct method, in the form of a "written conversation" between the researcher and the subjects.

In the processing and interpretation of data from this research we would use the statistical method (tables, diagrams, graphs).

Instruments In conducting the survey we used the questionnaire as a tool Analytic strategy Carrying out the survey based on the questionnaire involves going through some steps, such as: 
- setting research objectives.

- documentation.

- formulation of the main hypothesis.

- determining the group of participants.

- choosing the techniques for writing the questionnaire.

- gathering information and processing it.

- analysis of the results we obtained in relation to the proposed objectives.

- making the final research report

\section{Results}

Here are some results from the research chapter of the paper.

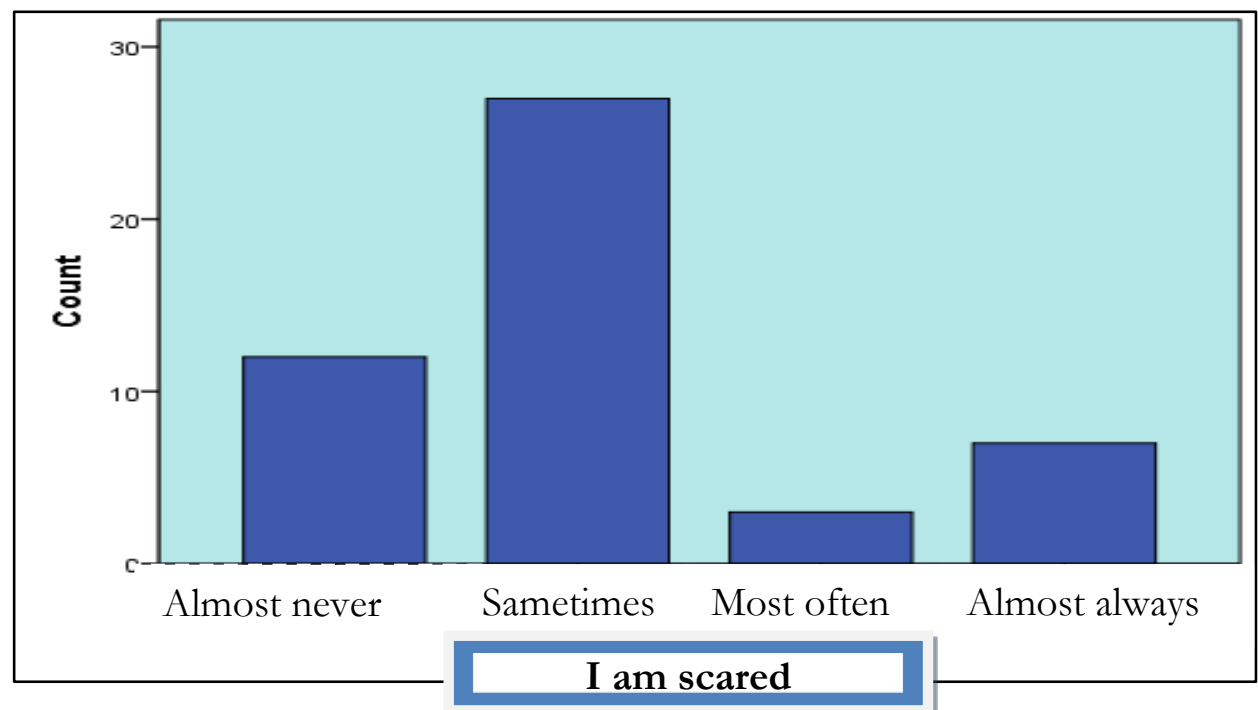

Regarding the level of fear that students feel at the time of some assessments, we can say that we have not at all worrying results. Approximately $80 \%$ of the students surveyed agreed with the statement that they "never" feel scared during an assessment.

Then comes a number of 13 students who say that during a test they do not feel scared "almost never". The rest of the students who were part of this case study stated that they feel scared "almost always", in a small number, and the others, in an extremely small percentage, stated that most of them or "feel scared when subjected to evaluations.

What we can observe is that, out of a number of 49 students interviewed, only 6 feel scared most of the time when they are subjected to evaluations. Thus, we are left with a number of 43 students who feel scared during tests only "sometimes" or "almost never".

Fig. 1. Source: SPSS statistics 


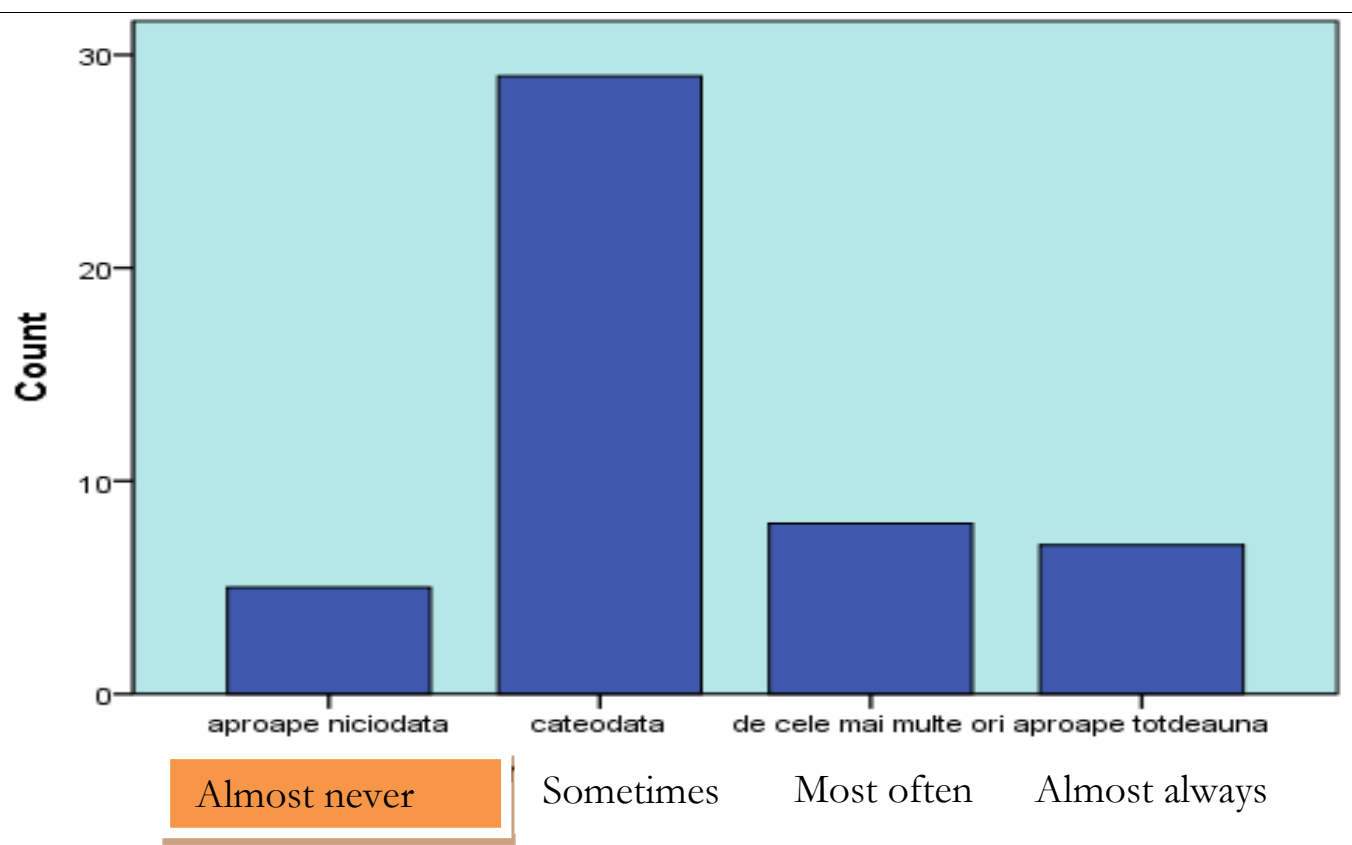

\section{I feel my heart beating faster than usual"}

As we see in this graph represented above, the evaluation of the subjects is done regarding the fear they feel when they are subjected to tests. Thus, we have a percentage of approximately 28 subjects, which represents a percentage of $60 \%$ of all students participating in the case study, who state that they only "sometimes" feel their beart beating faster than usual.

Of all the subjects, we are left with a percentage of $40 \%$ who state that during the tests they feel their heart beating faster than usual, it is usually "almost always", respectively 7, "most of the time", respectively 9 and "almost never", respectively 5.

Concluding the analysis of this graph, we can say that a large part of the students participating in the study, namely 60\%, do not feel fear during the tests.

Fig. 2. Source: SPSS statistics 


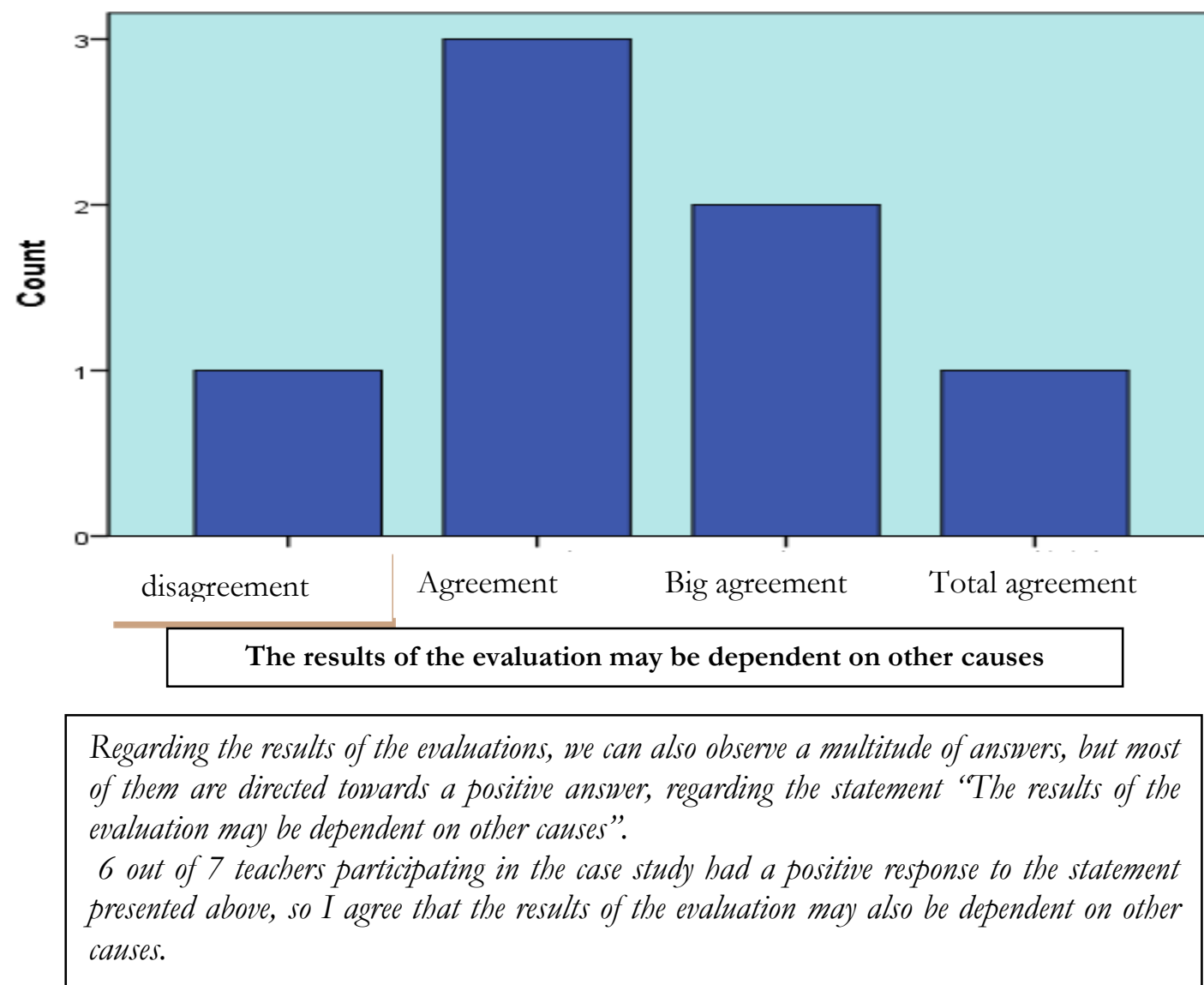

Fig. 3. Source: Spss statistics

\section{Discussions}

$\checkmark$ Test anxiety has been and is often ridiculed by some people who do not believe and have not experienced this. What is certain is that until you try something, or until you go through a situation, you have no way to make such statements.

$\checkmark$ We live in the century when testing, or as Sarason puts it, "the culture of testing" is extremely strong. Why? By the fact that, through certain exams or all kinds of tests, people can determine, for the most part, our performance and our intellectual capacity. And with the tests, comes the stress, and then there is the anxiety about the tests. 
$\checkmark$ The assessments that students are subjected to also come with an extremely high level of stress for them. Many students fail $100 \%$ when tested because they are stressed and anxious, so it is difficult for them to remember what they have learned or tremble and panic.

$\checkmark$ Through assessments, students should be tested for the knowledge they have gained in a course of study, but nowadays, students are often "required" to reproduce exactly what the teacher told them. And so anxiety occurs, students are stressed and forced to remember exactly what they learned in class and often get confused, make mistakes or have trouble remembering what they learned.

$\checkmark$ Test results should be a source for both teachers and parents to figure out where they went wrong or what needs to be improved. This should be the role of these tests, and students should understand this.

\section{Conclusions}

Following the data collection, their introduction into an SPSS statistical program and also the centralization of the results, the hypothesis was partially confirmed as only half of the participating students become anxious during some tests.

Therefore, after centralizing the results of the participating students, we came to the following conclusions:

- most of the time during the tests the students forget what they learned and even have problems remembering what they had to learn.

- the fact that students think more about what they don't know instead of thinking about what they know affects school results.

- $45 \%$ of participating students say that when they are tested, emotions appear "sometimes" -

- $60 \%$ of the participants stated that they do not feel fear during an evaluation

- About $90 \%$ of all students and participants in the study feel scared "sometimes" when they are tested.

- Some of the students' hands are shaking.

- After centralizing the results of the teachers participating in the study, we reached the following conclusions:

- All the teachers who participated in the study state that the evaluation of students helps them to know if the students reach the 
standards that have been proposed. a large part of the teachers say that the test results are a benchmark for them in terms of preparing students

- $90 \%$ of the respondents say that assessment is a method that helps students to improve their learning process

- The test results of the students are used in a constructive way by the participating teachers.

\section{References}

Chapell, M. S., Blanding, Z. B., Silverstein, M. E., Takahashi, M., Newman, B., Gubi, A., \& McCann, N. (2005). Test Anxiety and Academic Performance in Undergraduate and Graduate Students. Journal of Educational Psychology, 97(2), 268-274. https://doi.org/10.1037/0022-0663.97.2.268

Popa, C., Bonchis, L. \& Clipa, O. (2018) School assessment and test anxiety at primary school pupils. In O. Titrek, A. Zembrzuska, \& G. Sezen-Gultekin (Eds.), 4th International Conference on Lifelong educaton and Leadership for all, University Lower Silezia, Wroclaw, Polonia (Conference Proceeding book). pp. 867-874, https://docs.wixstatic.com/ugd/d546b1_838b960259e448e79c90 c577bf556d51.pdf,

Sarason, I. G. (1984). Stress, anxiety, and cognitive interference: Reactions to tests. Journal of Personality and Social Psychology, 46(4), 929-938. https://doi.org/10.1037/0022-3514.46.4.929

Shaked, C. A., Oksana, S., \& Lufi, D. (1996). Test Anxiety and its Effect on the Personality of Students with Learning Disabilities. Learning Disability Quarterly, 27(3), 176-184. https://doi.org/10.2307/1593667

Spielberger, C. D., \& Vagg, P. (1995). Validation of the State-Trait Distinction in Anxiety Research. Multivariate Behavioral Research, 10(3), 331-341. https://doi.org/10.1207/s15327906mbr1003 6

Veiga, F. H., Robu, V., Conboy, J., Ortiz, A., Carvalho, C., \& Galvão, D. (2016). Students' engagement in school and family variables: A literature review. Estudos de Psicologia (Campinas), 33(2), 187-197. https://doi.org/10.1590/1982-02752016000200002 